\title{
Issues About Retrieving Sea Surface Salinity in Coastal Areas From SMOS Data
}

\author{
Sonia Zine, Jacqueline Boutin, Philippe Waldteufel, Jean-Luc Vergely, Thierry Pellarin, and Pascal Lazure
}

\begin{abstract}
This paper aims at studying the quality of the sea surface salinity (SSS) retrieved from Soil Moisture and Ocean Salinity (SMOS) data in coastal areas. These areas are characterized by strong and variable SSS gradients [several practical salinity units (psu)] on relatively small scales: the extent of river plumes is highly variable, typically at kilometric and daily scales. Monitoring this variability from SMOS measurements is particularly challenging because of their resolution (typically $30-100 \mathrm{~km}$ ) and because of the contamination by the nearby land. A set of academic tests was conducted with a linear coastline and constant geophysical parameters, and more realistic tests were conducted over the Bay of Biscay. The bias of the retrieved SSS has been analyzed, as well as the root mean square (rms) of the bias, and the retrieved SSS compared to a numerical hydrodynamic model in the semirealistic case. The academic study showed that the Blackman apodization window provides the best compromise in terms of magnitude and fluctuations of the bias of the retrieved SSS. Whatever the type of vegetation cover, a strong negative bias, greater than 1 psu, was found when nearer than $36 \mathrm{~km}$ from the coast. Between 44 and $80 \mathrm{~km}$, the type of vegetation cover has an impact of less than a factor 2 on the bias, and no influence further than $80 \mathrm{~km}$ from the coast. The semirealistic study conducted in the Bay of Biscay showed a bias over ten days lower than 0.2 psu for distances greater than $47 \mathrm{~km}$, due to an averaging over various geometries (coastline orientation, swath orientation, etc.). The bias showed a weak dependence on the location of the grid point within the swath. Despite the noise on the retrieved SSS, contrasts due to the plume of the Loire River and the Gironde estuary remained detectable on ten-day averaged maps with an rms of $0.57 \mathrm{psu}$. Finally, imposing thresholds on the major axis of the measurements brought little improvement to the bias, whereas it increased the rms and could lead to strong swath restriction: a 49-km threshold on the major axis resulted in an effective swath of $800-900 \mathrm{~km}$ instead of $1200 \mathrm{~km}$.
\end{abstract}

Manuscript received June 1, 2006; revised October 24, 2006. This work was supported by the French project Terre, Océan, Surfaces Continentales et Atmosphère of the Centre National d'Etudes Spatiales ("Etudes préparatoires SMOS-Ocean") and is part of the SMOS Ocean Salinity Level 2 Prototype Processor development funded by the European Space Agency under European Space Research and Technology Centre (ESTEC) Contract 18933/05/NL/FF.

$\mathrm{S}$. Zine and $\mathbf{J}$. Boutin are with the Institut Pierre-Simon Laplace, Laboratoire d'Océanographie et du Climat-Expérimentation et Approches Numériques, Unité Mixte de Recherche Université Pierre et Marie Curie/Centre $\mathrm{Na}$ tional de la Recherche Scientifique/nstitut de Recherche pour le Développement/Muséum National d'Histoire Naturelle, 75252 Paris, France (e-mail: zine@locean-ipsl.upmc.fr; jb@locean-ipsl.upmc.fr).

P. Waldteufel is with the Institut Pierre-Simon Laplace, Service d'Aéronomie du Centre National de la Recherche Scientifique, 91731 Verrières le Buisson, France.

J.-L. Vergely is with ACRI-ST, 91731 Verrières le Buisson, France.

T. Pellarin is with the Laboratoire d'étude des Transferts en Hydrologie et Environnement (LTHE), 38041 Grenoble, France.

P. Lazure is with the Institut Français de Recherche pour l'Exploitation de la Mer (IFREMER), 29280 Plouzané, France.

Color versions of one or more of the figures in this paper are available online at http://ieeexplore.ieee.org.

Digital Object Identifier 10.1109/TGRS.2007.894934
Index Terms-Coastal areas, $L$-band radiometry, sea surface salinity (SSS) retrieval, Soil Moisture and Ocean Salinity (SMOS) mission.

\section{INTRODUCTION}

$\mathbf{O}$ CEAN salinity is a key parameter in oceanic and climate studies. Together with the ocean temperature, the salinity influences the density of the water masses and actively participates in their formation and circulation. In situ sea surface salinity (SSS) measurements, acquired by buoys and oceanographic or commercial ships, remain sparse and irregular, with large parts of the global ocean never sampled. In order to fill these gaps, two missions carrying $L$-band (1.4 GHz) radiometers have been recently proposed: the Soil Moisture and Ocean Salinity (SMOS, ESA) [1] and Aquarius (NASA/CONAE) [2] missions. Their objective is to estimate the SSS on a global scale, with a precision over the open ocean of 0.2 practical salinity units (psu) in $200 \times 200 \mathrm{~km}$ boxes on a ten-day average, so that the remotely sensed SSS should be suitable for assimilation into ocean circulation models [3], according to global ocean data assimilation experiment requirements. In the case of SMOS, this precision will be achieved after averaging numerous salinity retrievals, as every region of the global ocean will be visited by SMOS at least once every three days.

This paper deals with SSS retrieval from SMOS data in coastal zones. These zones are characterized by strong and variable SSS contrasts (several psu) on relatively small scales: the extent of river plumes is highly variable, typically at kilometric and daily scales. For instance, on the French continental shelf in the Bay of Biscay, in situ SSS measurements performed near islands between February 2000 and April 2003 showed an SSS seasonal variability of about 3 psu, and an interannual variability reaching 1 psu [4]. Over nine years of hydrographical data collected during cruises in the Bay of Biscay, the SSS has been found to vary from 30 to 36 psu, with a spatial extent of these SSS contrasts that can reach $120 \mathrm{~km}$ in spring [5]. The variability is expected to be higher (over 10 psu over several hundreds kilometers) for larger river plumes, such as the Amazon's or the Mississippi's.

Monitoring this variability from $L$-band satellite radiometric measurements is particularly challenging because of their limited resolution (typically $30-100 \mathrm{~km}$ ) and because $L$-band measurements over the coastal ocean are contaminated by the nearby land: recent global simulations of $L$-band land brightness temperatures $(\mathrm{Tb})$ showed a range of about $140 \mathrm{~K}$ to $300 \mathrm{~K}$ [6], compared to approximately $100 \mathrm{~K}$ for the ocean. 


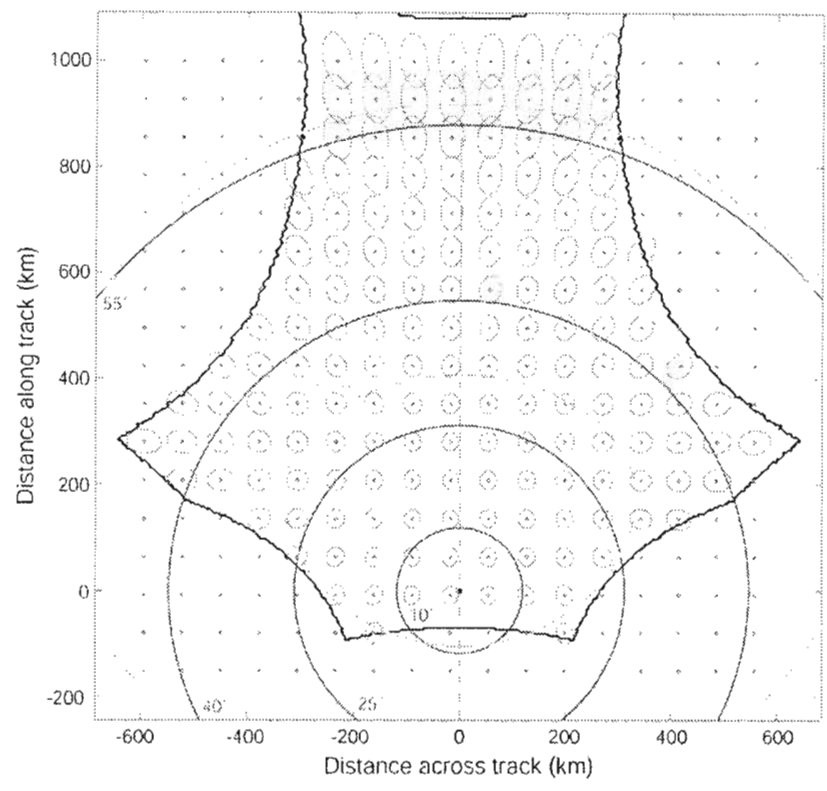

Fig. 1. SMOS FOV (thick black line). The light gray (red in the color version) ellipses represent $3-\mathrm{dB}$ synthetic antenna pattern contours (Blackman exact apodization window). The $40-$ and $90-\mathrm{km}$ major axis limits appear in bold medium gray (green). The thin black (blue) circles represent the locations of the incidence angles $10^{\circ}, 25^{\circ}, 40^{\circ}$, and $55^{\circ}$. One dwell line is also shown (dashed line)

The objective of this paper was to assess to what extent SSS variability in coastal areas can be monitored with SMOS. On the one hand, a set of academic tests were conducted with a linear coastline and constant geophysical parameters. On the other hand, more realistic tests were conducted over the Bay of Biscay, where the Loire and Garonne Rivers create SSS plumes, particularly in spring.

The methods and data used are described in Section II. The impact of different apodization windows used in the image reconstruction to deduce SMOS Tb from the measured visibilities is investigated in Section III. Under the SMOS configuration, an ocean grid point is seen by several measurements with various incidence angles, various resolutions, and various ellipticities. The effects of thresholds on the major axis of measurement ellipses and of the location of the measurements within the swath are also investigated in Section III. Results are discussed and summarized in Section IV.

\section{Methods AND DATA}

A complete description of the SMOS 2-D interferometer can be found in [1], [7]. Two-dimensional fields of $\mathrm{Tb}$ are reconstructed in the antenna reference frame. The Stokes vector at the antenna level is linked to the Stokes vector at sea surface level by a linear matrix, that depends on the antenna gain pattern and on the geometry of observation [8]. The sensor images a 2-D field of view (FOV) in which Tb is acquired at various incidence angles and spatial resolutions, therefore any given point on the Earth is observed several times in successive locations within the FOV as the satellite moves ahead, along "dwell lines" parallel to the subsatellite track (Fig. 1)

\section{A. Direct Emissivity Models}

Following the method used in [9], sea surface emissivity is simulated using the two-scale model described in [10]. Sea water permittivity is given by the Klein and Swift parameterization [11] and the wave spectrum is modeled using Durden and Vesecky parameterization [12] multiplied by 2, as proposed by Yueh [13]. With this model, for sea surface temperatures (SST) around $15^{\circ} \mathrm{C}$, the sensitivity of $\mathrm{Tb}$ (at nadir) to SSS is typically $-0.5 \mathrm{~K} \cdot \mathrm{psu}^{-1}$, of $\mathrm{Tb}$ to wind speed (WS) $0.2 \mathrm{~K} \cdot \mathrm{m}^{-1} \cdot \mathrm{s}$, and of $\mathrm{Tb}$ to SST close to $0 \mathrm{~K} \cdot{ }^{\circ} \mathrm{C}^{-1}$.

For land, two types of responses were considered: a soil covered with low vegetation (typically, grasslands or crops), and a forest-covered soil. We approximated land Tb with two simplistic models. In the case of a soil covered with low vegetation

$$
\mathrm{Tb}_{\text {land } 1}=\mathrm{Tb}_{\text {sea }}(\theta, \varphi)+\Delta \mathrm{Tb}
$$

with $\Delta \mathrm{Tb}=100 \mathrm{~K}, \theta$ the incidence angle and $\varphi$ the azimuth angle at the center of a SMOS measurement. In case of a forest-covered soil, we considered $\mathrm{Tb}$ independent of $\theta$ and $\varphi$

$$
\mathrm{Tb}_{\text {land2 }}=280 \mathrm{~K} \text {. }
$$

In order to investigate whether these models are representative, we compared them to global simulations of $L$-band $\mathrm{Tb}$ over land for year 1988, at different incidence angles and in vertical and horizontal polarizations [6]. Mean $\mathrm{Tb}(\overline{\mathrm{Tb}})$ and their standard deviations $(\sigma)$ were computed for pixels containing less than $5 \%$ of open water surfaces, over the globe and over the Bay of Biscay. From Fig. 2, it can be seen that the annual variation of $\overline{\mathrm{T} \mathrm{b}_{\text {globe }}}$ and of $\overline{\mathrm{T} \mathrm{b}_{\text {Biscay }}}$ always ranges between $\mathrm{Tb}_{\text {land1 }}$ (lower bound) and $\mathrm{Tb}_{\text {land2 }}$ (higher bound). In horizontal polarization, $\overline{\mathrm{Tb}_{\text {globe }}} \pm 2 \sigma_{\mathrm{Tb}_{\text {globe }}}$ and $\overline{\mathrm{Tb}_{\text {Biscay }}} \pm$ $2 \sigma_{\mathrm{T} b_{\text {Biscay }}}$ also remain within the $\left[\mathrm{Tb}_{\text {land } 1}, \mathrm{~Tb}_{\text {land } 2}\right]$ interval throughout the year. In vertical polarization at $50^{\circ}$ incidence angle [Fig. 2(e)], $\mathrm{Tb}_{\text {land } 1}$ overestimates $\overline{\mathrm{Tb}_{\text {globe }}}-\sigma_{\mathrm{Tb}} \mathrm{F}_{\text {flobe }}$ and

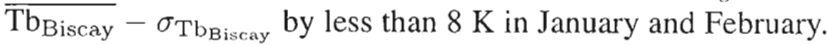
However, the effect of this overestimation was neglected, as it is small compared to the land-sea $\mathrm{Tb}$ contrast, limited in time, and measurements acquired at incidence angles greater or equal to $50^{\circ}$ represent about $17 \%$ of all measurements acquired within the SMOS FOV. This indicates that $\mathrm{Tb}_{\text {land1 }}$ and $\mathrm{Tb}_{\text {land } 2}$ represent, respectively, the lower and upper bounds of $\mathrm{Tb}$ in about $90 \%$ of the cases in horizontal polarization, and $70 \%$ in vertical polarization.

\section{B. Integration Over the Synthetic Antenna Pattern}

The synthetic antenna consists in 69 antenna elements distributed along three arms equally spaced, resulting in a planar Y-shaped structure. Complex visibility functions are obtained from the cross correlations between simultaneous measurements of each pair of antenna elements. The image reconstruction links the visibilities to the field of Tb by an integral relationship somewhat similar to a Fourier transform. The equivalent gain pattern of the synthetic antenna is determined by the limited size of the interferometer and the apodization function applied to measured visibilities [14]. The 3-dB 
(a) Tb at $0^{\circ}$ inc. angle

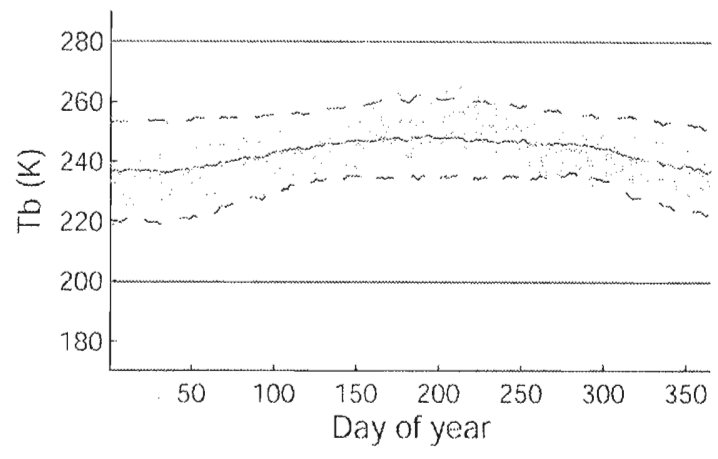

(b) $\mathrm{Tb}_{\mathrm{h}}$ at $40^{\circ}$ inc. angle

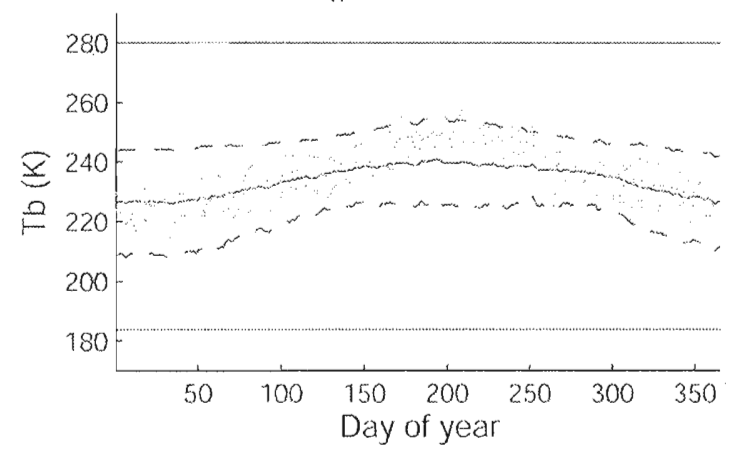

(d) $\mathrm{Tb}_{\mathrm{h}}$ at $50^{\circ} \mathrm{inc}$, angle

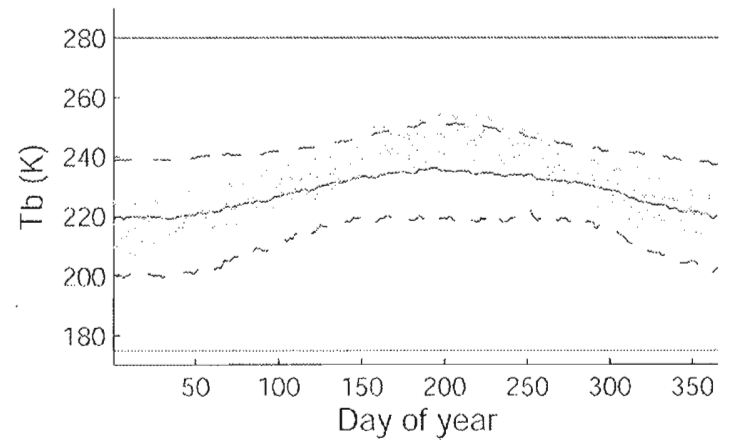

(c) Tb at $40^{\circ}$ inc, angle

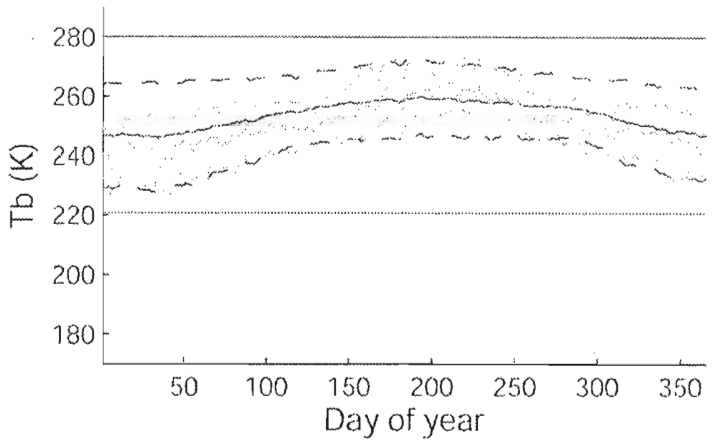

(e) $\mathrm{Tb}_{v}$ at $50^{\circ}$ inc. angle

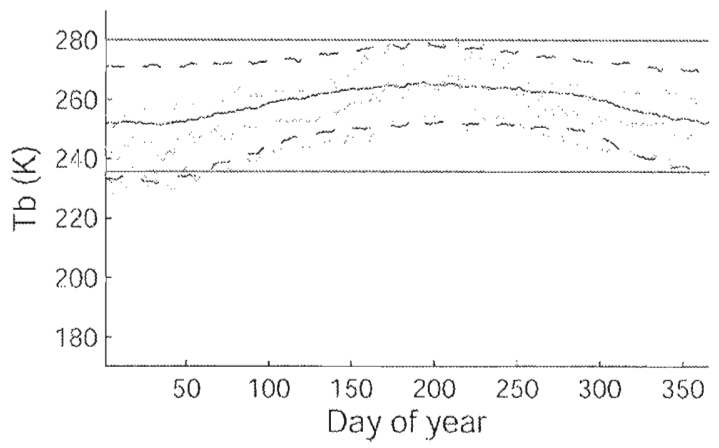

Fig. 2. Temporal evolution of simulated $L$-band land $\mathrm{Tb}$ at (a) $0^{\circ}$ incidence angle, $40^{\circ}$ incidence angle in (b) horizontal and (c) vertical polarizations, and $50^{\circ}$ incidence angle in (d) horizontal and (e) vertical polarizations. Land Tb simulated for pixels containing less than $5 \%$ of open water surfaces are averaged over the globe (light gray solid line, or blue solid line in the color version: $\overline{\mathrm{T}} \bar{b}_{\text {globe }}$, light gray or blue dashed lines: $\overline{\mathrm{Tb}_{\text {globe }}} \pm \sigma_{\mathrm{Tb}} \mathrm{b}_{\text {globe }}$ ) and over the Bay of Biscay (black or green solid line: $\overline{\text { Tb Biscay }}$, black or green dashed lines: $\overline{\text { Tb Biscay }} \pm \sigma_{\mathrm{Tb}_{\text {Biscay }}}$ ). Tb computed with the simplistic model are shown in medium gray dashed-dotted lines or red solid lines (upper line: forest case, lower line: soil with low vegetation cover case).

width of this $2-\mathrm{D}$ weighting function is approximately $2.2^{\circ}$. The ground weighting function (GWF) is obtained through intersecting the synthetic antenna pattern function with the surface of the Earth.

The measured $\mathrm{Tb}$ is related to $\mathrm{Tb}^{\prime}$ in element area by integrating $\mathrm{Tb}^{\prime}$ weighted by the GWF. The integration is computed in the plane tangent to the surface of the Earth

$$
\mathrm{Tb}=\iint_{x, y} \operatorname{Tb}^{\prime}(x, y) \operatorname{GWF}(x, y) d x d y .
$$

$x$ and $y$ define the position (in kilometers in the tangent plane) of the measurement in the SMOS instantaneous FOV and correspond to an incidence angle $\theta$ and an azimuth angle $\varphi$.
Assuming that the variations of $\mathrm{Tb}_{\text {land }}$ and $\mathrm{Tb}_{\text {sca }}$ with $\theta$ and $\varphi$ are linear within the GWF, $\mathrm{Tb}^{\prime}$ is taken out of the integral and computed using geophysical "equivalent parameters." These equivalent parameters (SSS, SST, WS) are integrated over a "mean GWF," i.e., a GWF the characteristics of which correspond to the mean characteristics of all the GWF within the SMOS FOV. Neglecting nonlinear effects of $\theta$ and $\varphi$ was tested and found to generate retrieval biases always smaller than $0.03 \mathrm{psu}$ in salinity. The equivalent parameters approach has been validated in SMOS soil moisture studies, for geophysical parameters much more variable than over the ocean [15]. These studies also showed that the main contribution of inhomogeneities in the GWF to Tb variability could be described as the sum of contributions of surface fractions weighted by the 
GWF. Hence, if $\mathrm{GWF}_{\theta, \varphi}(x, y)$ represents the GWF for given incidence and azimuth angles, the sea fraction is defined as follows:

$$
f_{\text {sea }}(\theta, \varphi)=\int_{-150 \mathrm{~km}}^{+150 \mathrm{~km}+150 \mathrm{~km}} \int_{-150 \mathrm{~km}} \operatorname{GWF}_{\theta, \varphi}(x, y) \operatorname{Bs}(x, y) d x d y
$$

where $\operatorname{Bs}(x, y)$ is equal to 1 if the surface element is covered with sea, 0 otherwise. With this definition, $f_{\text {sea }}$ is complemented to unity by the weighted land fraction. Thus, $\mathrm{Tb}$ in coastal areas, $\mathrm{Tb}_{\text {coast }}$, can be deduced from both $\mathrm{Tb}_{\text {land }}$ and $\mathrm{Tb}_{\text {sea }}$ weighted by land and sea fractions

$$
\operatorname{Tb}_{\text {coast }}(\theta, \varphi)=f_{\text {sea }}(\theta, \varphi) \operatorname{Tb}_{\text {sea }}(\theta, \varphi)+\left[1-f_{\text {sea }}(\theta, \varphi)\right] \operatorname{Tb}_{\text {land }}
$$

The integration in (4) is computed for $x$ and $y$ between -150 and $+150 \mathrm{~km}$ with a $5-\mathrm{km}$ step. The main contribution to the integral is found between -100 and $+100 \mathrm{~km}$.

Because the GWF has negative side lobes, fractions can in principle be slightly negative. The sum of fractions being normalized to 1 , fractions can also be slightly greater than 1 . Nevertheless, since negative side lobes have a limited extent, such cases are very seldom after the integration of (4) has been carried out.

The ellipses of resolution of the SMOS measurements correspond to the $3-\mathrm{dB}$ synthetic antenna pattern contours represented in Fig. 1. The major axis of these ellipses is referred to as "major axis" in this paper.

\section{Retrieval Model}

A description of the retrieval method can be found in [7] A maximum likelihood Bayesian approach was used, taking advantage of the a priori information available about physical parameters. In the antenna reference frame, the Tb modeled using the direct models described in Section $\Pi-\mathrm{A} \mathrm{Tb}^{\text {mod }}$, were fitted to a set of measured $\mathrm{Tb} \mathrm{Tb}^{\text {meas }}$ acquired at various incidence angles and spatial resolutions by minimizing the cost function

$$
\chi^{2}=\sum_{n} \frac{\left[\mathrm{Tb}_{n}^{\text {meas }}-\mathrm{Tb}^{\text {mod }}\left(\theta_{n}, p_{i}, \ldots,\right)\right]^{2}}{\sigma_{n}^{2}}+\sum_{i} \frac{\left[p_{i}-p_{i 0}\right]^{2}}{\sigma_{i 0}^{2}}
$$

$\mathrm{Tb}_{n}^{\text {meas }}$ are simulated at incidence angles $\theta_{n}$ using the direct model, with the addition of a Gaussian noise of variance $\sigma_{n}^{2} ; p_{i}$ are physical parameters that influence the Tb (i.e., SSS, SST, wind components, .. ); $p_{i 0}$ are a priori estimates of the $p_{i}$ with a priori variances $\sigma_{i 0}^{2}$. Typically, $\sigma_{n}$ ranges from $2 \mathrm{~K}$ to $4 \mathrm{~K}$ and the square roots of a priori variances for SST and WS are equal to $1{ }^{\circ} \mathrm{C}$ and $1.5 \mathrm{~m} \cdot \mathrm{s}^{-1}$. SSS is not constrained ( $\sigma_{\mathrm{SSS}}=$ $100 \mathrm{psu}$ ). A general least square iterative algorithm was used to retrieve the $p_{i}$ values that minimize the cost function. This also provided variance estimates $\sigma_{i}^{2}$ on the retrieved parameters.

In order to study the effect of land contamination, retrievals were conducted with $\mathrm{Tb}^{\text {mod }}$ computed assuming no land contribution and a homogeneous ocean surface.

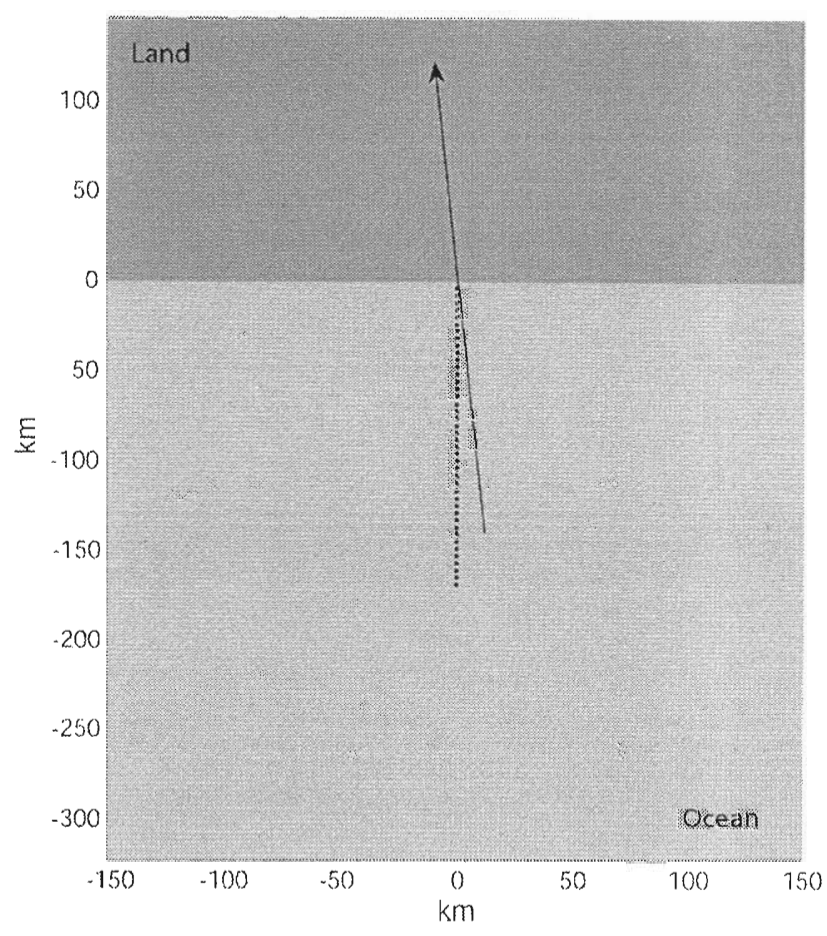

Fig. 3. Coastline configuration for the academic study. Grid points are represented by black dots and the subsatellite track by an arrow.

The error on the retrieved SSS was given by the difference between retrieved SSS and reference SSS.

\section{Academic Study}

In this part, all relevant parameters were controlled in order to separate their effects on the quality of the retrieved SSS and ease results interpretation. The selected configuration was a linear coastline parallel to the equator. Geophysical parameters were set to constant values: 35 psu for SSS, $20{ }^{\circ} \mathrm{C}$ for SST, and $2 \mathrm{~m} \cdot \mathrm{s}^{-1}$ for WS. The retrieval was conducted over grid points $4 \mathrm{~km}$ apart, located close to the center of the FOV on a line perpendicular to the coastline (Fig. 3). The major axis of the measurements are oriented in a direction very close to the perpendicular to the coastline, maximizing land contamination effects (as the tilting of the satellite track with respect to the South-North direction is small, its influence is expected to be negligible).

Sea fractions corresponding to this configuration are shown in Fig. 4 for various incidence angles and distances to the coast. At $28 \mathrm{~km}$ from the coast, the sea fraction decreases when the incidence angle increases, indicating that land is gradually entering the main lobe of the GWF. For greater distances to the coast $(48-128 \mathrm{~km})$, the sea fraction oscillates when incidence angles increase (note that fractions greater than 1 are obtained): this is due to land alternately entering negative and positive side lobes of the GWF.

We studied the influence of the following parameters on the bias of the retrieved SSS with respect to the distance to the coast. 


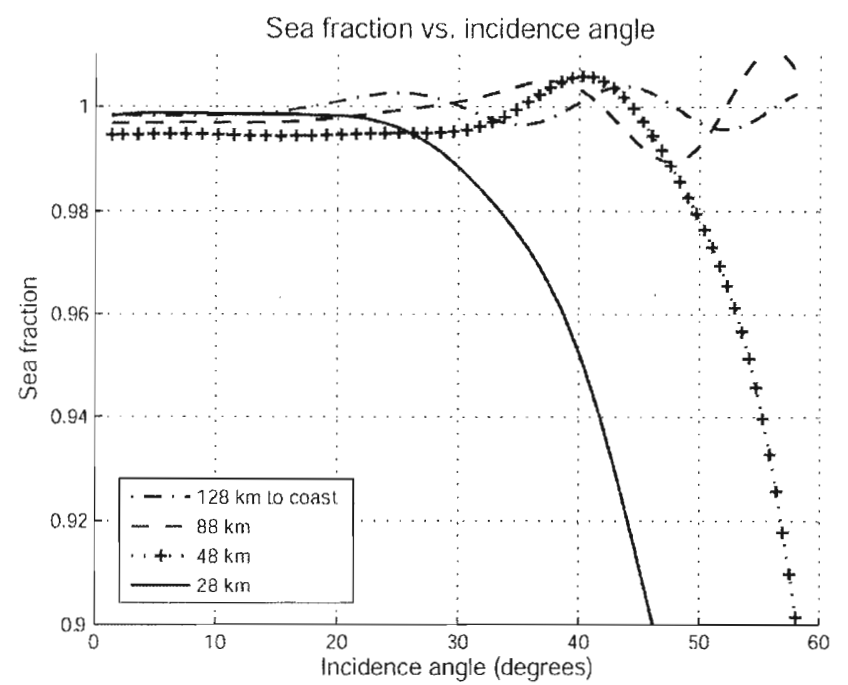

Fig. 4. Sea fractions versus incidence angle, for various distances to coast and measurements taken in the center of the swath along the subsatellite track shown in Fig. 3. Academic study, Blackman window.

- Various thresholds on the major axis: Discarding measurements with large major axes is a way to limit land contamination (lower bias), however it also decreases the number of measurements used for the retrieval, hence increasing the root mean square (rms).

- Two types of land cover: Low vegetation and forest.

- Three alternative apodization windows (Fig. 5): Rectangular, Blackman (exact) and Kaiser (with the $\alpha$ parameter set to 13). The choice of the apodization window is a tradeoff between improving the spatial resolution of the reconstructed $\mathrm{Tb}$ and reducing the Gibbs phenomenon that introduces oscillations in the reconstructed $\mathrm{Tb}$ [16].

\section{E. Semirealistic Study}

A study was conducted with a realistic coastline in the Bay of Biscay, covering longitudes from $0^{\circ} \mathrm{W}$ to $6^{\circ} \mathrm{W}$ and latitudes from $43^{\circ} \mathrm{N}$ to $49^{\circ} \mathrm{N}$. In order to investigate the impact of the location within the swath on the error on the retrieved SSS, two orbits were selected: an ascending orbit with a subsatellite track coinciding with the French Atlantic coastline [Fig. 6(a)], and a descending orbit with a subsatellite track located approximately $300 \mathrm{~km}$ east from the same coastline [Fig. 6(b)].

Realistic SSS and SST fields were simulated by a highresolution $(5 \mathrm{~km})$ numerical 3-D hydrodynamic model, MARS 3-D [17]. Within the hydrostatic assumption, the model solves the three equations of motion and of continuity, allowing the calculation of currents, temperature, salinity, and dispersion of dissolved elements. We selected simulations conducted over the March-April 2001 period when strong cross-shore SSS gradients occurred [Fig. 7(a)], due to a mean south-west wind direction from September to March, high river runoffs and relatively low vertical mixing in spring [5]. At that time, SST was around $12{ }^{\circ} \mathrm{C}-15^{\circ} \mathrm{C}$ (Fig. 8).

The WS was set to a constant value of $10 \mathrm{~m} \cdot \mathrm{s}^{-1}$. Previous studies have shown that the SSS error is very sensitive to SST range, but little sensitive to WS range [9]. Hence, using a (a)

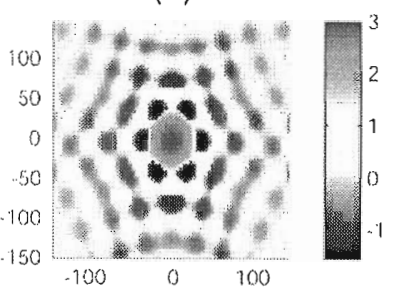

(c)

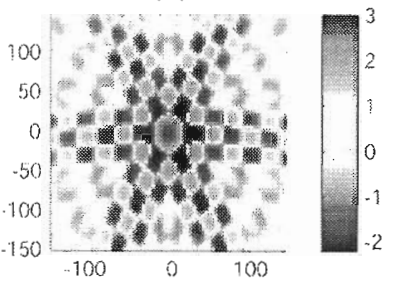

(e)

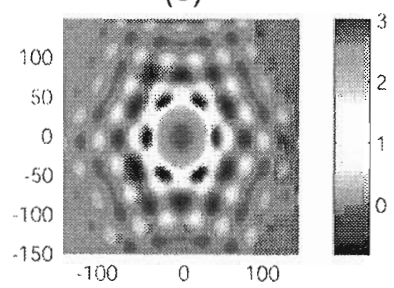

(b)

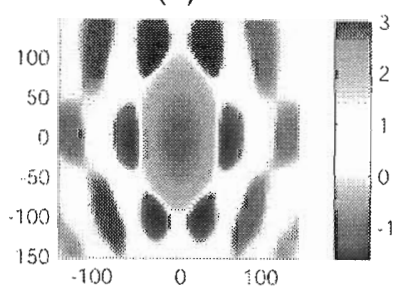

(d)

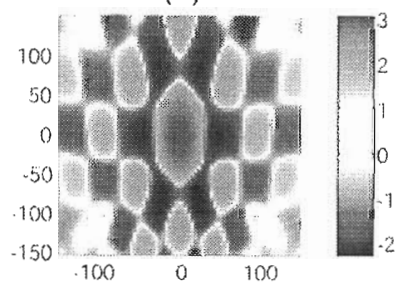

(f)

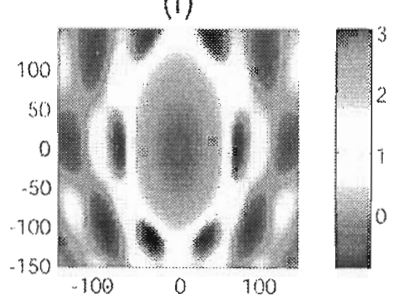

Fig. 5. GWFs corresponding to various apodization windows and incidence angles: Blackman (exact) at (a) $1^{\circ}$ and (b) $58^{\circ}$ incidence angle, rectangular at (c) $1^{\circ}$ and (d) $58^{\circ}$ incidence angle, Kaiser $(\alpha=13)$ at (e) $1^{\circ}$ and (f) $58^{\circ}$ incidence angle. The axes labels are distance in kilometers. The color scale is defined as follows: considering $\varepsilon=10^{-3} \max |G W F|$, the scaled $\mathrm{GWF}, \mathrm{GWF}_{\mathrm{SC}}$, is given by $\mathrm{GWF}_{\mathrm{SC}}=\log _{10}(\mathrm{GWF} / \varepsilon)+\varepsilon$ for $\mathrm{GWF}>\varepsilon$, by $\mathrm{GWF}_{\mathrm{SC}}=-\log _{10}(-\mathrm{GWF} / \varepsilon)-\varepsilon$ for $\mathrm{GWF}<-\varepsilon$, and by $\mathrm{GWF}_{\mathrm{SC}}=$ GWF for $-\varepsilon \leq \mathrm{GWF} \leq \varepsilon \cdot \max |\mathrm{GWF}|$ is equal to $1.6 \cdot 10^{-2}$ for (a), 3.4 $10^{-3}$ for (b), $4.3 \cdot 10^{-2}$ for (c), $9.7 \cdot 10^{-3}$ for (d), $1.1 \cdot 10^{-2}$ for (e), $2.3 \cdot 10^{-3}$ for $(f)$.

realistic WS would not lead to major differences in SSS error, as long as the error on WS remains the same.

Retrievals were also performed over fields of constant geophysical parameters, with an SSS of 35 psu, an SST of $12{ }^{\circ} \mathrm{C}$ and a WS of $10 \mathrm{~m} \cdot \mathrm{s}^{-1}$, in order to assess the land contamination-induced biases of the retrieved SSS.

The land surface response was that of a soil covered with low vegetation, and the simulations were performed using the Blackman apodization window. Retrievals were conducted over the same 15-km hexagonal grid (ISEA grid, [18]) that will be used in the SMOS operational processor. As in the academic study, various thresholds on the major axis were tested.

SSS errors (i.e., differences between retrieved and reference SSS) were computed for each grid point and then averaged over all grid points having the same range of distance to the coast, within $5-\mathrm{km}$ intervals, in order to obtain the bias $b$ on the retrieved SSS

$$
b=\frac{\sum_{i=1}^{N}\left(\mathrm{SSS}_{i}-\mathrm{SSS}_{i}^{\mathrm{ref}}\right)}{N}
$$

where $\operatorname{SSS}_{i}$ (respectively $\operatorname{SSS}_{i}^{\mathrm{rcf}}$ ) is the retrieved (respectively reference) SSS on grid point $i$, and $N$ the number of grid points. 
(a)

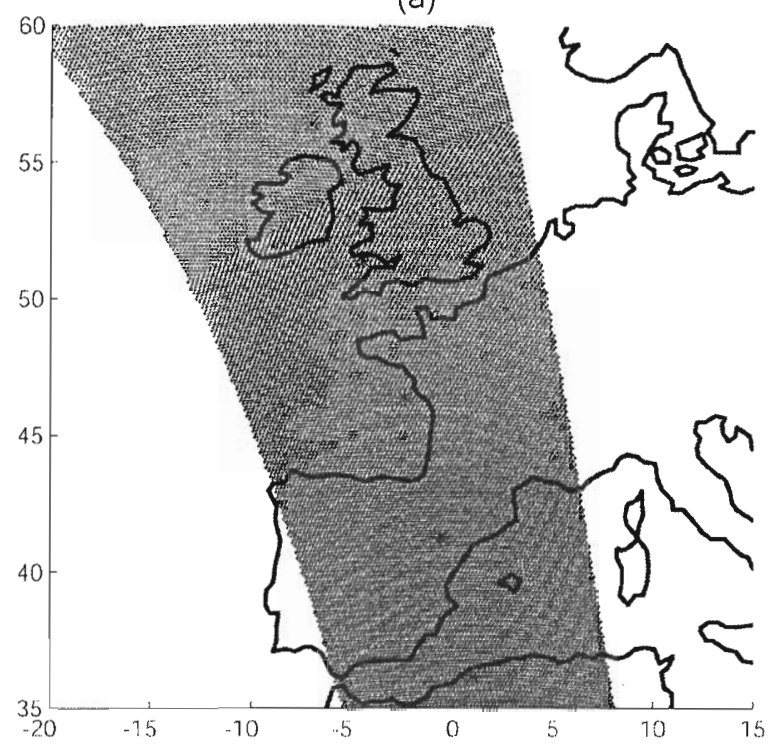

(b)

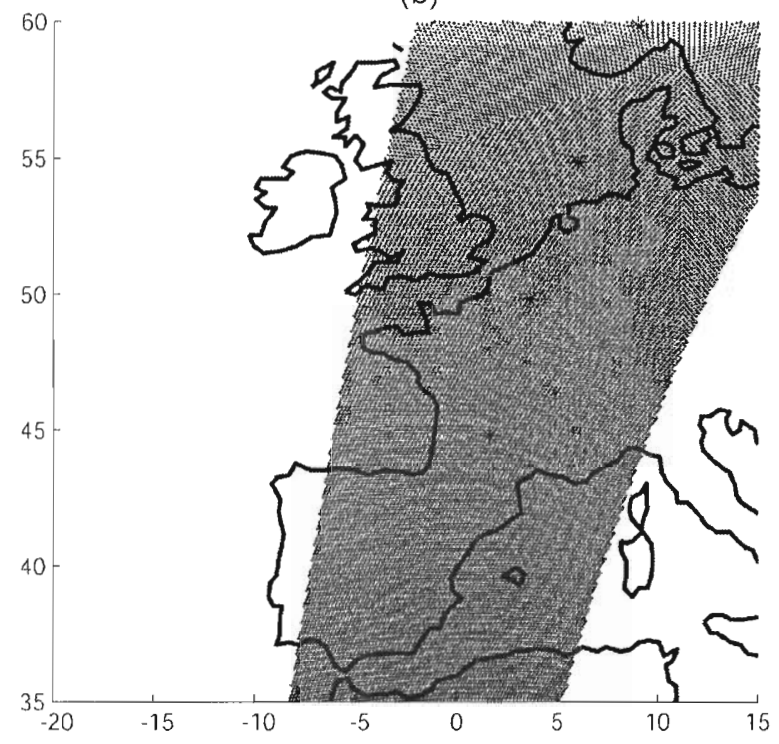

Fig. 6. (a) Ascending and (b) descending orbits used in the semirealistic study. The subsatellite track is represented by black stars, ISEA grid points by black dots.

The rms of the bias was given by

$$
\mathrm{rms}=\sqrt{\frac{1}{N-1} \sum_{i=1}^{N}\left(\mathrm{SSS}_{i}-\mathrm{SSS}_{i}^{\mathrm{ref}}\right)^{2}-b^{2} .}
$$

In order to investigate possible improvements of the rms, we performed time integrations: Simulations and retrievals were run over a two-month period and for each grid point, and the retrieved SSS was averaged over ten days (i.e., 15 satellite passes between April 14 and 24, 2001) and one month (43 passes between March 30 and April 29, 2001). To save computation time, we limited the SMOS FOV to $600 \mathrm{~km}$ in front of the subsatellite point, instead of $1000 \mathrm{~km}$ in the rest of this paper. This increases the standard deviation of the error (a)

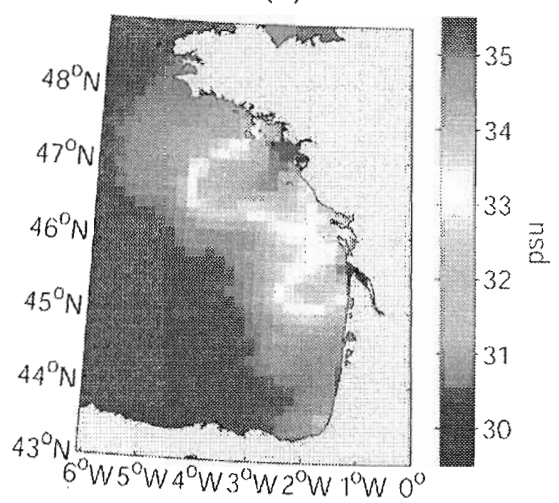

(b)

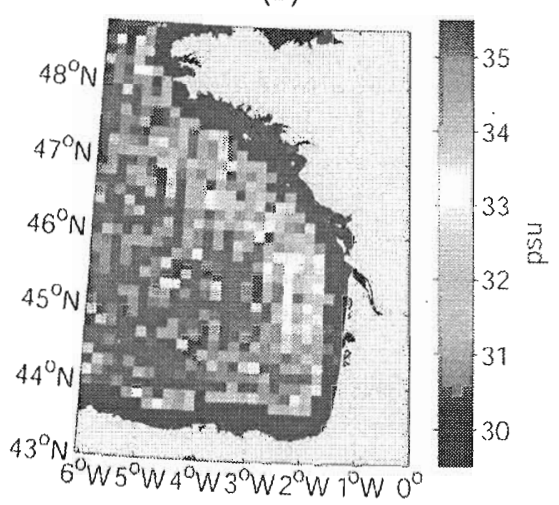

Fig. 7. (a) SSS simulated by the MARS 3-D model (5-km resolution degraded to $15 \mathrm{~km}$, date of simulation: April 21, 2001). (b) Retrieved SSS (realistic radiometric noise). Blackman window, soil with low vegetation cover, no threshold on the major axis, ascending orbit.

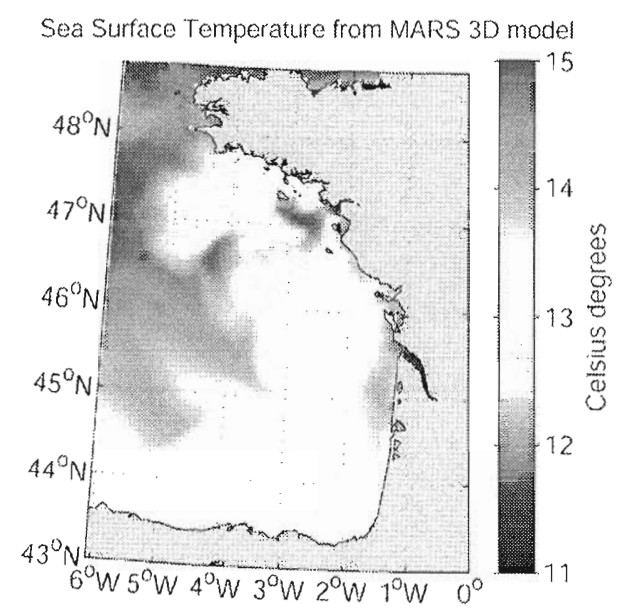

Fig. 8. SST simulated by the MARS 3-D model (5-km resolution, date: April 21, 2001).

on the SSS over the open ocean by $15 \%$, which is acceptable for the purpose of this paper.

\section{F. Radiometric Noise and Auxiliary Parameters Uncertainties}

In the academic case, we divided the radiometric noise on Tb by 20 and we set the a priori uncertainties on auxiliary 
TABLE I

RADIOMETRIC NOISE ON Tb AND UNCERTAINTIES ON AUXILIARY Parameters Used to Evaluate the Bias on the Retrieved SSS

\begin{tabular}{|c|c|c|c|c|c|c|c|}
\hline & & $\sigma_{n}(\mathrm{~K})$ & $\begin{array}{c}\sigma_{W / S n} \\
\left(\mathrm{~m} \mathrm{~s}^{-1}\right)\end{array}$ & $\begin{array}{l}\sigma_{S S 5 \%} \\
\left({ }^{\circ} \mathrm{C}\right)\end{array}$ & Sections & Figures & Remarks \\
\hline \multicolumn{2}{|c|}{ Academic study } & $0.1-0.2$ & 0.075 & 0.1 & III.A & $\begin{array}{l}\text { Fig. 9, } \\
\text { Fig. 10, } \\
\text { Fig. 11 }\end{array}$ & $\begin{array}{l}\text { Error on retrieved } \\
\text { SSS } 20 \text { times lower } \\
\text { than realistic error }\end{array}$ \\
\hline \multirow{2}{*}{$\begin{array}{l}\text { Scmi- } \\
\text { reatistic } \\
\text { study }\end{array}$} & 1 pass & $0.2-0.4$ & 0.15 & 0.1 & $\begin{array}{l}\text { liI.B.1) } \\
\text { and 2) }\end{array}$ & $\begin{array}{l}\text { Fig. } \\
\text { 12-a, } \\
\text { Fig. } \\
\text { 14-a }\end{array}$ & $\begin{array}{l}\text { Error on retrieved } \\
\text { SSS } 10 \text { times lower } \\
\text { than realistic error }\end{array}$ \\
\hline & $\begin{array}{l}10 \text {-day and } \\
1 \text {-inonth } \\
\text { averages }\end{array}$ & $2-4$ & 1.5 & I & III.B.3) & $\begin{array}{l}\text { Fig. } \\
16-a\end{array}$ & $\begin{array}{l}\text { Realistic error on } \\
\text { retrieved SSS }\end{array}$ \\
\hline
\end{tabular}

parameters to $\sigma_{\mathrm{SST} 0}=0.1{ }^{\circ} \mathrm{C}$ and $\sigma_{\mathrm{WSO}}=0.075 \mathrm{~m} \cdot \mathrm{s}^{-1}$ in order to reduce the number of retrievals needed to obtain a very precise estimate of the bias, which could then be estimated from one retrieval. Since SSS errors in the semirealistic case were mostly analyzed on averages over several grid points, we divided the noise and uncertainties by 10 in that case. Assuming that the errors are Gaussian, this was equivalent to averaging the error on the retrieved SSS over 400 and 100 retrievals, respectively. For a given grid point, 100 retrievals correspond to about three months of data and 400 retrievals to about one year of data, according to the characteristics of the SMOS orbit as implemented in the simulator used in this paper (salinity retrieval software [19]). In the semirealistic case, we also computed the rms of the bias obtained with a realistic noise on $\mathrm{Tb}$ $\left(\sigma_{n}\right)$ and realistic a priori uncertainties on auxiliary parameters.

The noise and uncertainties are summarized in Table I.

\section{RESUlts}

\section{A. Academic Study}

Tests on various apodization windows (Section III-A1) and thresholds on the major axis (Section III-A2) were conducted for a soil covered with low vegetation. Patterns are similar for a forest-covered soil, quantitative differences are shown in Section III-A3).

1) Apodization Windows: The bias on the retrieved SSS depends on the apodization window used (Fig. 9). The bias is lower than 0.2 psu for distances greater than 56 and $60 \mathrm{~km}$ from the coast for the Blackman and the Kaiser windows, respectively, and than $140 \mathrm{~km}$ for the rectangular window. The main lobe of the rectangular window [Fig. 5(c) and (d)] has the finest spatial resolution, however the magnitude of the side lobes leads to high land contamination even far from the coast. Consequently, SSS bias fluctuations are high as far as $140 \mathrm{~km}$ from the coast. On the other hand, the side lobes of the Kaiser apodization window [Fig. 5(e) and (f)] are strongly attenuated whereas its main lobe has the coarsest resolution, hence it leads to very low bias fluctuations $( \pm 0.07$ psu for distances to the coast greater than $80 \mathrm{~km}$ ) but also to a strong land contamination closer than $60 \mathrm{~km}$ to the coast. On the whole, the Blackman window [Fig. 5(a) and (b)] represents the best compromise.

Fig. 9 was computed for a $65-\mathrm{km}$ threshold on the major axis; similar tendencies were observed for thresholds ranging from 40 to $80 \mathrm{~km}$ (not shown).

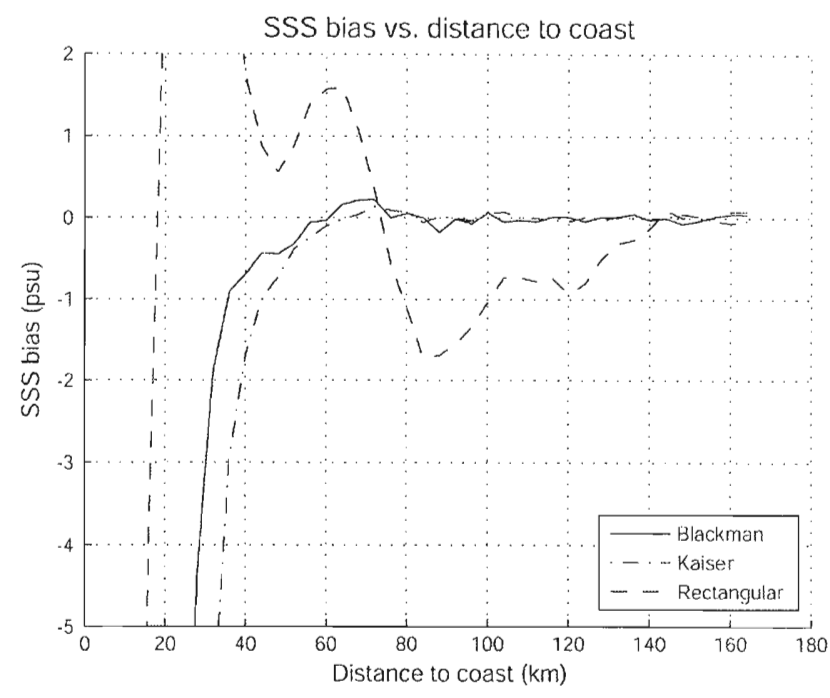

Fig. 9. SSS bias versus distance to coast for different apodization windows. Academic study, soil with low vegetation cover, major axis $\leq 65 \mathrm{~km}$.

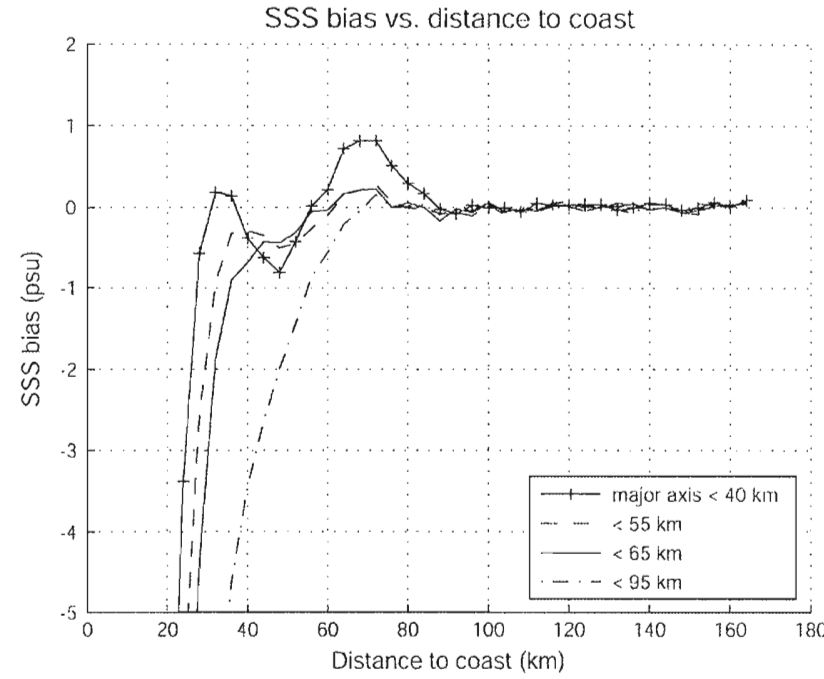

Fig. 10. SSS bias versus distance to coast for different thresholds on the major axis. Academic study, Blackman window, soil with low vegetation cover.

2) Thresholds on the Major Axis: Fig. 10 shows biases on retrieved SSS versus distance to the coast for thresholds on the major axis ranging from 40 to $95 \mathrm{~km}$, using a Blackman apodization window. For thresholds between 55 and $95 \mathrm{~km}$, biases are lower than $0.2 \mathrm{psu}$ when further than $75 \mathrm{~km}$ from the coast. For a $40-\mathrm{km}$ threshold, biases are larger than $0.2 \mathrm{psu}$ up to $84 \mathrm{~km}$ from the coast and oscillate strongly between 25 and $84 \mathrm{~km}$, due to land contamination. The $95-\mathrm{km}$ threshold shows little oscillation, and a more gradual decrease, with a bias increasing in absolute value from 0.2 psu at $64 \mathrm{~km}$ from the coast to $4.6 \mathrm{psu}$ at $36 \mathrm{~km}$. Biases become lower than $1 \mathrm{psu}$ in absolute value from $32 \mathrm{~km}$ from the coast for the $55-\mathrm{km}$ threshold, from $36 \mathrm{~km}$ from the coast for the $65-\mathrm{km}$ threshold, and from $56 \mathrm{~km}$ for the $95-\mathrm{km}$ threshold. All biases are similar for distances greater than $88 \mathrm{~km}$.

3) Land Cover Type: SSS biases for a soil covered with low vegetation and for a forest-covered soil are shown on Fig. 11. 


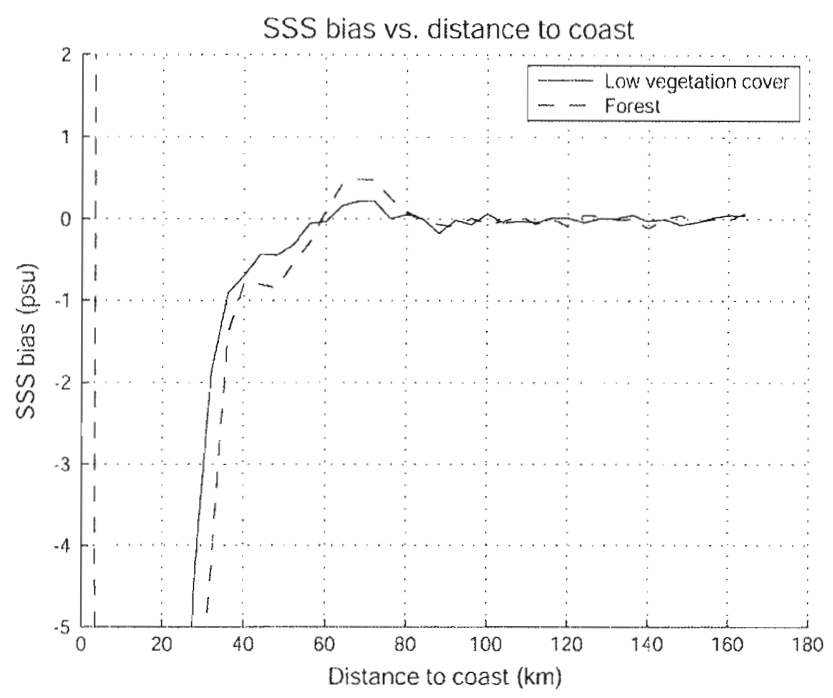

Fig. 11. SSS bias versus distance to coast for different land covers. Academic study, Blackman window, major axis $\leq 65 \mathrm{~km}$.

Between 40 and $80 \mathrm{~km}$, the bias for a forested soil is about twice the bias for a soil covered with low vegetation, due to a stronger land contamination. For distances to the coast greater than $80 \mathrm{~km}$, the bias for a forested soil is lower than 0.2 psu and comparable to the one for a soil covered with low vegetation.

\section{B. Semirealistic Study}

I) Ascending Orbit (Center of Swath Coinciding With Coastline): Fig. 12(a) shows the bias on the SSS versus the distance to coast, for various thresholds on the major axis and a radiometric noise divided by 10 . Averages are computed over 10 grid points minimum and 356 grid points maximum, 24 grid points being the median.

As expected, near the coast the bias increases in absolute value for thresholds on the major axis increasing from 49 to $90 \mathrm{~km}$. The bias obtained with no threshold on the major axis is slightly higher than for the $90-\mathrm{km}$ threshold, indicating the small impact of the additional measurements taken into account by thresholds greater than $90 \mathrm{~km}$. A comparison with Fig. 10 shows that bias values obtained in the semirealistic study are lower than those of the academic study, with a bias becoming lower than $0.2 \mathrm{psu}$ in absolute value for all thresholds and for distances to the coast greater than $52 \mathrm{~km}$. This shorter distance than the one obtained in the academic study is due to the averaging over numerous geometric configurations within grid points located at the same distance from the coast, resulting in an average over very different land contaminations.

The rms (computed with a realistic noise) ranges from 0.6 to 1.8 psu for distances to the coast greater than $37 \mathrm{~km}$ for all thresholds [Fig. 12(b)]. This is comparable to the values obtained in [9] over open oceans: at $12{ }^{\circ} \mathrm{C}$, SSS random uncertainties range from about 0.9 to 3 psu, depending on the location across track. For distances lower than $37 \mathrm{~km}$, the rms of the bias is high and varies with the threshold on the major axis, indicating land contamination. It appears from both

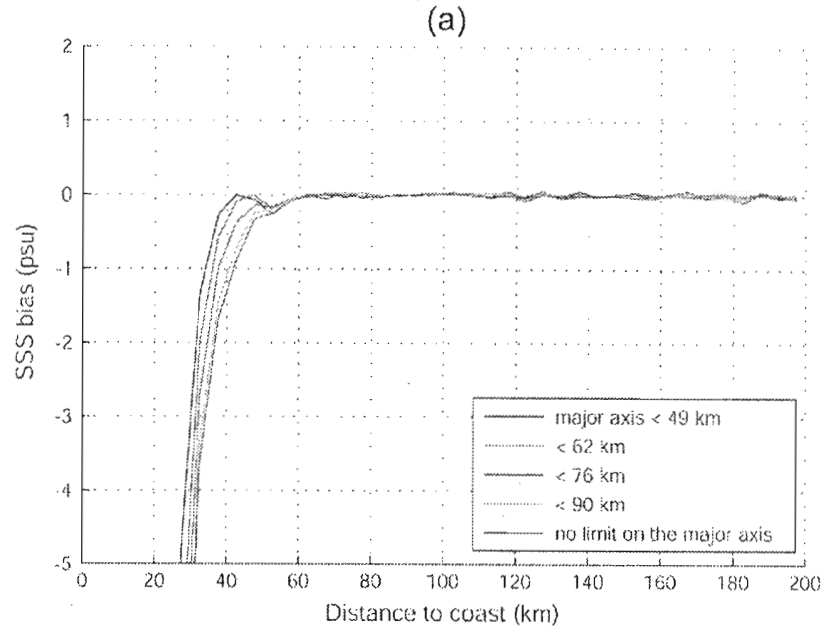

(b)

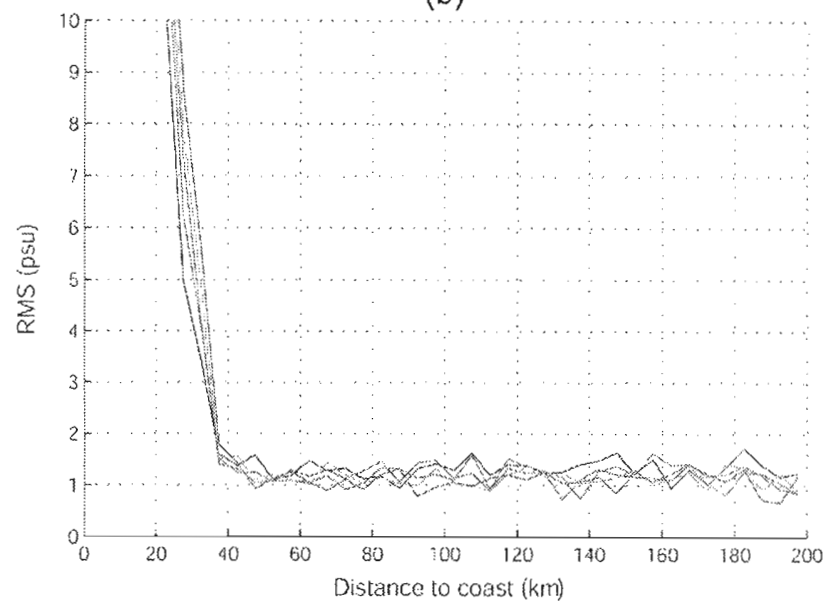

Fig. 12. (a) SSS bias versus distance to coast (radiometric noise and a priori uncertainties on auxiliary parameters divided by 10 ) and (b) rms versus distance to coast (realistic radiometric noise) for different thresholds on the major axis. Semirealistic study, Blackman window, soil with low vegetation cover ascending orbit.

Fig. 12(a) and (b) that, in this configuration (i.e., center of swath coinciding with the coastline), thresholds on the major axis have no impact on the bias and rms further than $52 \mathrm{~km}$ from the coast.

The bias and the rms obtained with homogeneous reference SSS and SST were similar to those obtained with heterogeneous reference SSS and SST. This indicated that the contribution of oceanic heterogeneities to biases and rms was marginal, the main contributions originated in land contamination and radiometric noise on $\mathrm{Tb}$ (not shown).

The SSS error map [Fig. 13(a)] represents the retrieved SSS minus the reference SSS (i.e., SSS simulated with MARS 3-D) for the ascending orbit, with a radiometric noise divided by 10 and no threshold on the major axis. As expected, the strongest differences are found close to the coast, where SSS are systematically underestimated, since $\mathrm{Tb}$ increase due to land contamination. Nevertheless, very high salinities (above 40 psu) are retrieved in a few isolated pixels very close to the coast. For most grid point located closer than $20 \mathrm{~km}$ to the coast, either the algorithm does not converge, either it converges to very low 
(a)

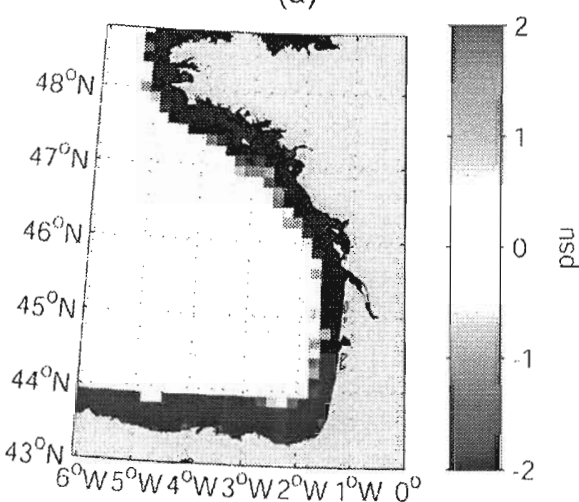

(b)

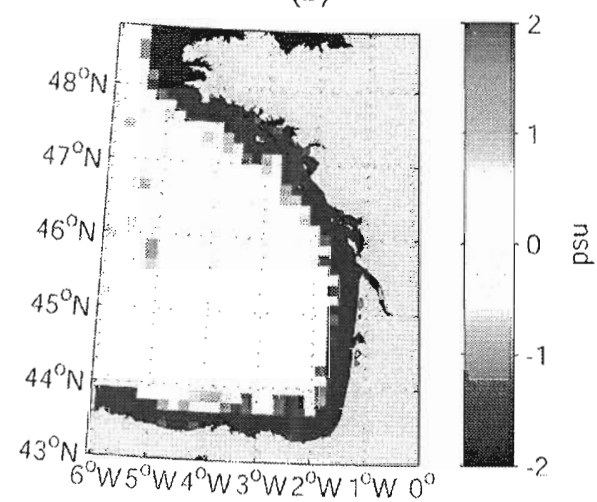

(c)

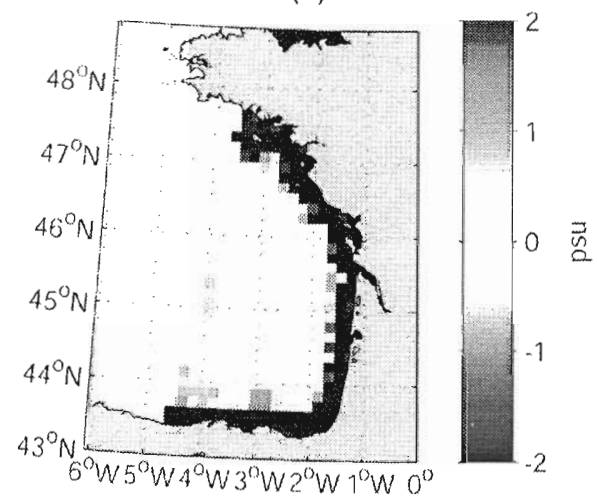

Fig. 13. Maps of SSS error (difference between retrieved SSS and reference SSS simulated by MARS 3-D model) that would be obtained by averaging 100 satellite passes: (a) Ascending orbit, no threshold on the major axis, (b) descending orbit, no threshold on the major axis, (c) descending orbit, major axis $\leq 49 \mathrm{~km}$. Blackman window, soil with low vegetation cover.

(less than $10 \mathrm{psu}$ ) or very high salinities, sometimes even to negative salinities. This is due to the fact that measured $\mathrm{Tb}$ were outside the validity range of the model used in the inversion and that the algorithm extrapolated values out of the range of the lookup table used to compute $\mathrm{Tb}^{\text {mod }}$, which could lead to aberrant results. None of these very low or very high salinities were obtained further than $40 \mathrm{~km}$ from the coast.

The spatial extent of areas of strong negative differences reach a $2-3$ pixel width along the western and southern coasts of Brittany compared to a 1-2 pixel width along the Landes and (a)

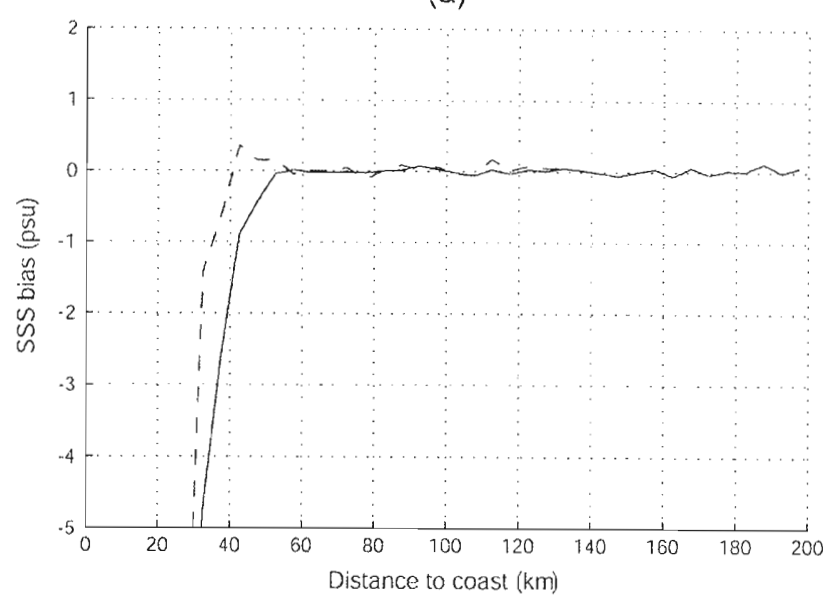

(b)

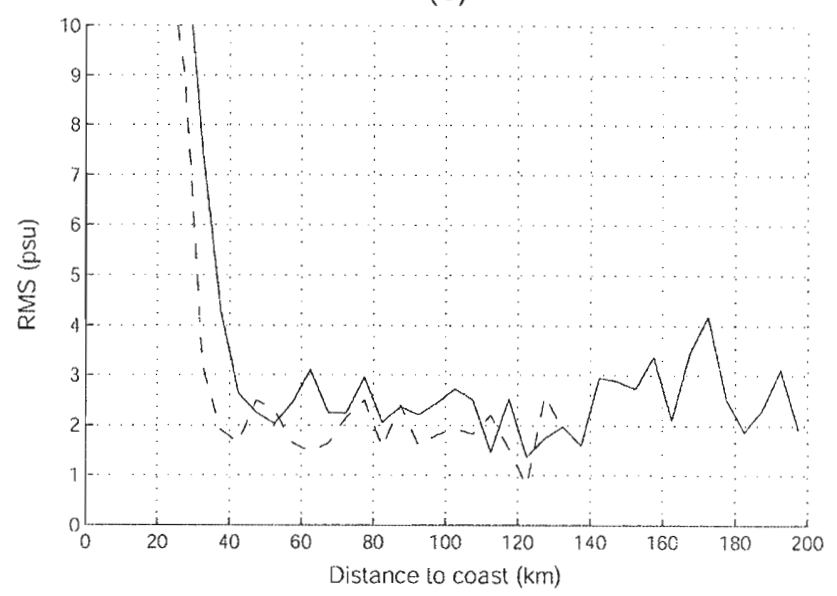

Fig. 14. (a) SSS bias versus distance to coast (radiometric noise and a prior uncertainties on auxiliary parameters divided by 10 ) and (b) rms versus distance to coast (realistic radiometric noise) for major axis $\leq 49 \mathrm{~km}$ (dashed line) and no threshold on the major axis (solid line). Semirealistic study, Blackman window, soil with low vegetation cover, descending orbit.

Spanish coast. This is due to the presence of numerous islands off Brittany, adding to land contamination.

A map of the retrieved SSS (with a realistic noise) is shown on Fig. 7(b). Despite the noise on the retrieved SSS and the spatial extent of the contamination by the land, both SSS gradients due to the discharge of the Loire River and the Gironde estuary can still be seen. However, a quantitative use of such maps would require temporal integration in order to reduce the noise and provide an estimation of the location and spatial extension of river plumes (see Section III-B3).

2) Descending Orbit (Center of Swath Located $300 \mathrm{~km}$ East From Coastline): The SSS error maps obtained with no threshold on the major axis [Fig. 13(b)] and a major axis lower than $49 \mathrm{~km}$ [Fig. 13(c)] are very similar until $4^{\circ} \mathrm{W}-5^{\circ} \mathrm{W}$. Beyond this limit, SSS is no longer retrieved in the second case due to the severe restriction imposed on the major axis: from about $400-450 \mathrm{~km}$ from the satellite track to the edge of the swath, all measurements are discarded by the threshold on major axis length. 
(a)

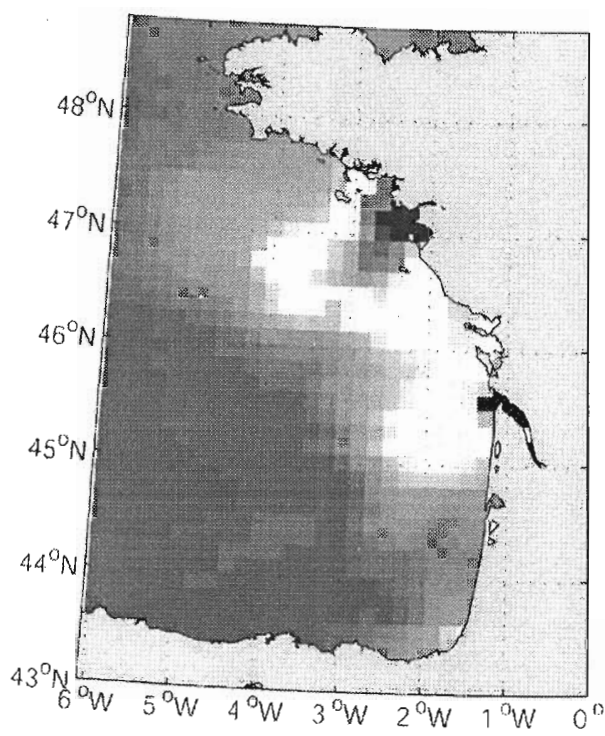

(b)

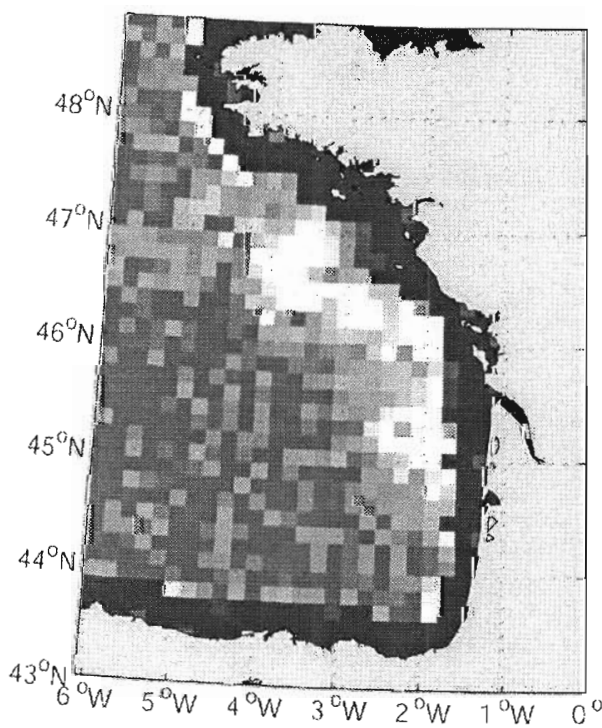

(c)
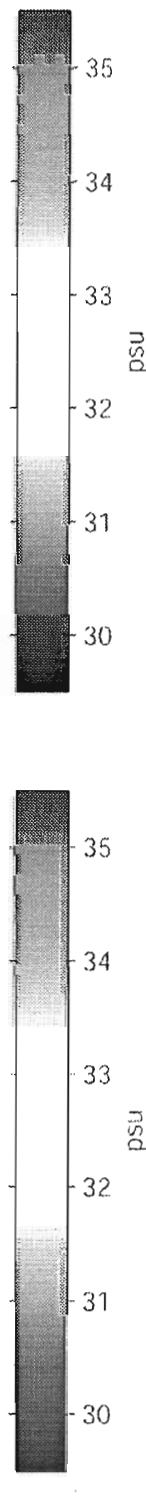

(d)
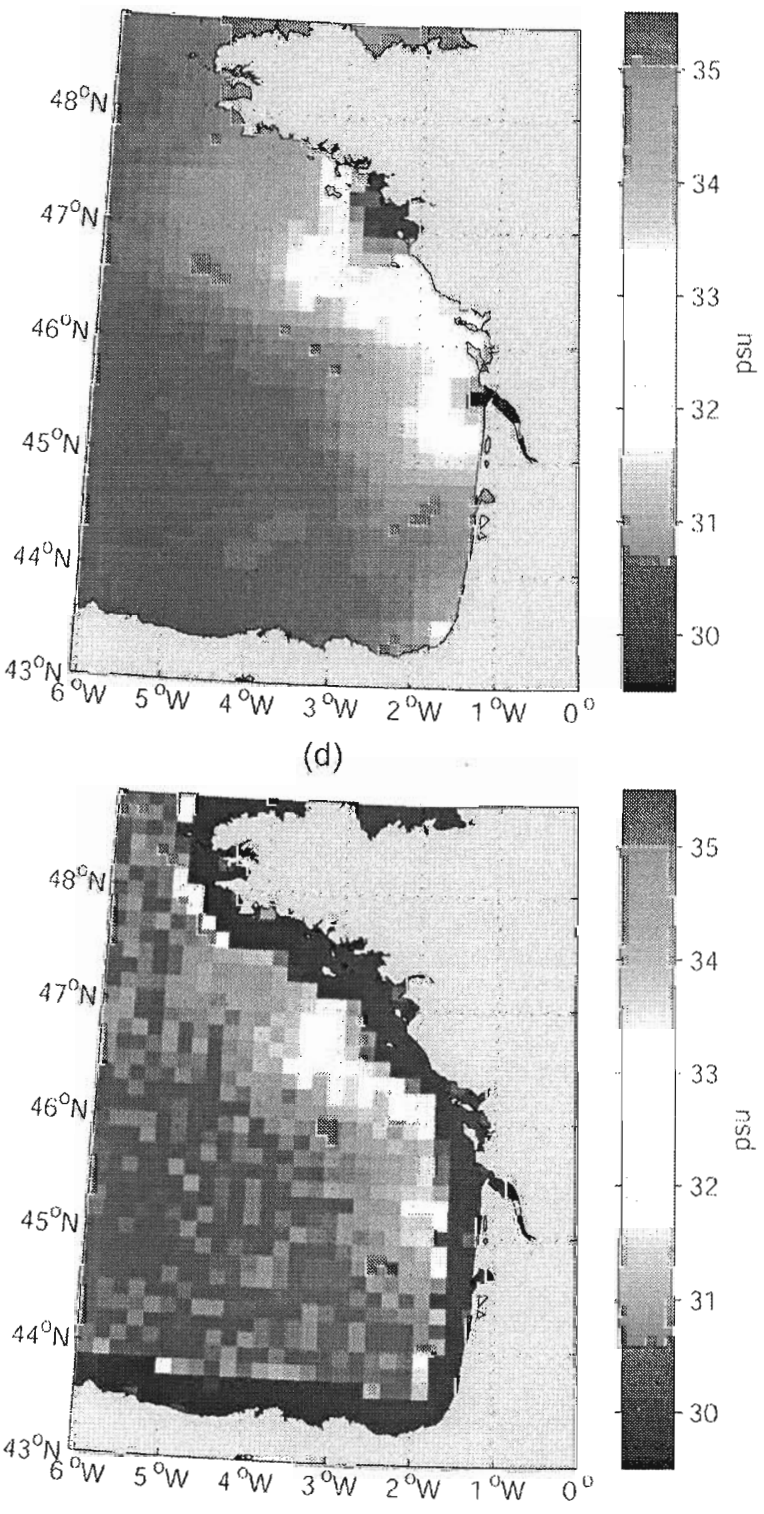

Fig. 15. (a) Maps of ten-day averages of reference and (b) retrieved SSS, and of (c) one-month averages of reference and (d) retrieved SSS. Blackman window, soil with low vegetation cover, realistic radiometric noise, no threshold on the major axis, FOV limited to $600 \mathrm{~km}$ in front of the subsatellite point.

The SSS bias [Fig. 14(a)] is weakly affected by the location in the swath: it remains lower than 0.2 psu for distances greater than $52 \mathrm{~km}$ from the coast in both cases $(49-\mathrm{km}$ threshold and no threshold). This is in agreement with previous studies, that showed that SSS bias created by Tb bias varies by less than $20 \%$ from swath center toward swath edge [19]. On the other hand, the rms [Fig. 14(b)] reaches about 2 psu at $50 \mathrm{~km}$ from the coast for both cases (49-km threshold and no threshold), and increases for greater distances up to 4 psu at $170 \mathrm{~km}$, where the grid points are in the edge of the swath. The rms is higher for the descending orbit than for the ascending orbit [Fig. 12(b)], being strongly dependent on the location in the swath [9].

3) Temporal Integration: Maps of retrieved and reference SSS averaged over ten days are shown on Fig. 15(a) and (b).
Integration over such a period preserves most of the spatial extent of the SSS gradients while reducing the noise: in the Loire River plume (between $46^{\circ} \mathrm{N}$ and $47.5^{\circ} \mathrm{N}$, and $2^{\circ} \mathrm{W}$ and $4^{\circ} \mathrm{W}$ ), for distances further than $40 \mathrm{~km}$ from the coast, the error on the retrieved SSS is within -1.18 and 1.7 psu, the mean bias is -0.003 psu and the rms is 0.57 psu (not shown). These values are very similar to the ones obtained over the whole map (not shown). A one-month integration [Fig. 15(c) and (d)] significantly decreases the error (less than 1 psu in the Loire River plume, not shown) on the retrieved SSS, although the spatial variability of the SSS due to river discharges is smoothed. However, this map still allows the determination of the limit between coastal waters (SSS lower than 35 psu) and open sea waters (SSS higher than 35 psu). 
(a)

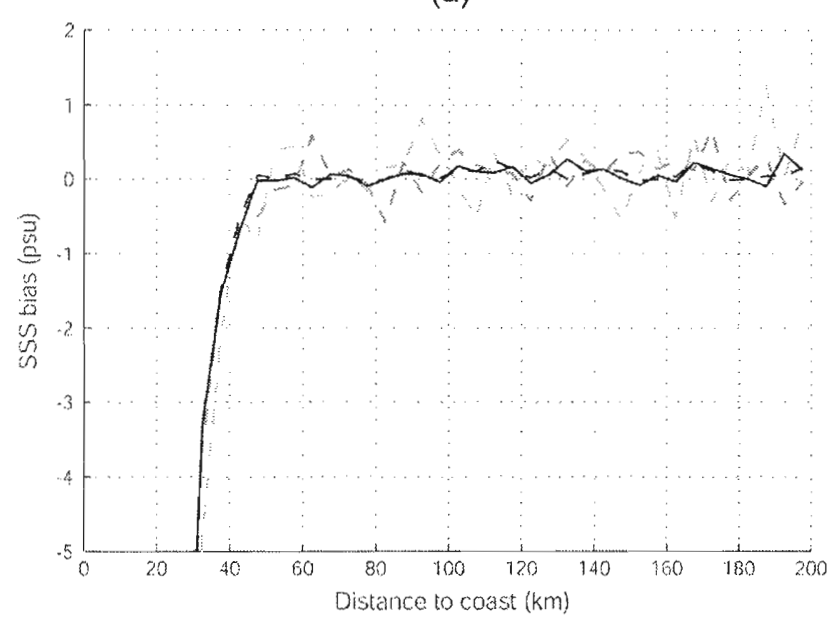

(b)

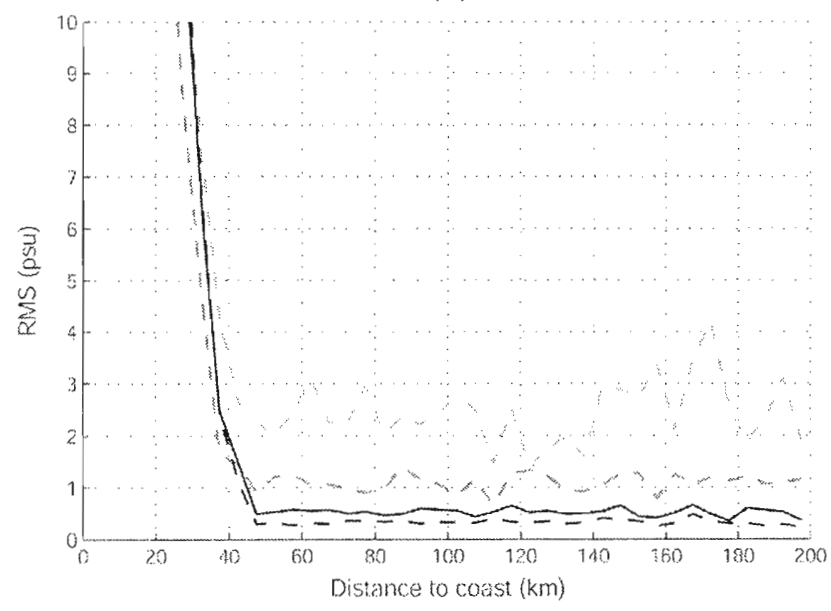

Fig. 16. (a) SSS mean bias versus distance to coast and (b) rms versus distance to coast computed over: ten-day (black solid line), one-month (black dashed line). Values obtained for one pass are recalled in gray (ascending pass: dark gray dashed line, descending pass: light gray dashed line). Semirealistic study, Blackman window, soil with low vegetation cover, realistic radiometric noise, no threshold on the major axis. The temporal averages were computed with a FOV limited to $600 \mathrm{~km}$ in front of the subsatellite point.

SSS bias as a function of distance to coast and averaged over ten days and one month are shown on Fig. 16(a). Temporal integration reduces the noise on the bias, with a bias becoming close to zero for distances greater than $47 \mathrm{~km}$. An integration over a one-month period results in a bias very similar to the one obtained with an integration over a ten-day period.

As expected, temporal integration reduces the rms [Fig. 16(b)]. For distances greater than $47 \mathrm{~km}$, the rms is significantly improved by the temporal integration: whereas it ranges from 1 to 4 psu for 1 satellite pass, it decreases to less than 0.7 psu for a ten-day integration, and to less than 0.5 psu for a one-month integration.

\section{DisCUSSION AND CONCLUSION}

The aim of this paper was to assess the quality of the SSS retrieved from SMOS data in coastal areas. An academic study showed that the Blackman apodization window provides the best compromise in terms of retrieved SSS bias magnitude and fluctuations, confirming what was expected in [7]. In a pessimistic geometric configuration, with the Blackman window and a soil covered with low vegetation, SSS could be retrieved with a bias lower than 0.2 psu for distances to the coast greater than $75 \mathrm{~km}$. The use of thresholds on the major axis of the measurements slightly reduced the bias but at the cost of higher fluctuations. The influence of land cover was also investigated, showing that for distance to the coast greater than $80 \mathrm{~km}$, the bias no longer depended on the type of vegetation cover.

A semirealistic study conducted in the Bay of Biscay gave slightly better results than the academic study in terms of bias with respect to the distance to the coast, with a bias lower than $0.2 \mathrm{psu}$ in absolute value for distances greater than $47 \mathrm{~km}$, due to an averaging over various geometries (coastline orientation, etc.) over ten days. The error on the retrieved SSS was comparable to previous results [9] and depended strongly on the location in the swath, whereas the latter's influence on the bias was weak. Restricting the major axis brought little improvement to the bias on the retrieved SSS, whereas it increased the error on the retrieved SSS and could lead to strong swath width limitation: a $49-\mathrm{km}$ threshold on the major axis implies that $200-250 \mathrm{~km}$ of data at both swath edges are unusable for retrieval, resulting in an effective swath of $800-900 \mathrm{~km}$ instead of $1300 \mathrm{~km}$.

The contribution of oceanic heterogeneities to biases and rms was marginal: the main contributions originated in land contamination and radiometric noise on $\mathrm{Tb}$. Temporal integration reduced the error on the retrieved SSS, and significantly decreased the rms for distances to the coast greater than $47 \mathrm{~km}$. Further than $47 \mathrm{~km}$ from the coast, a ten-day integration resulted in an rms of 0.57 psu over areas of strong SSS contrasts: this value is suitable for the monitoring of SSS variability in coastal areas and of the spatial extent of river plumes such as the Loire's.

These results were obtained neglecting land contribution in the retrieval; they could probably be improved by using an inversion method that takes into account the presence of land in the lobe. However, this approach would be computationally heavy and requires knowledge of the land $\mathrm{Tb}$ with very good accuracy.

\section{ACKNOWLEDGMENT}

The authors would like to thank G. Caudal and G. Reverdin for fruitful discussions, and one anonymous reviewer for very constructive remarks. The authors would also like to thank N. Martin for computing advices and for his efficient support for the processing of land $\mathrm{Tb}$.

\section{REFERENCES}

[1] Y. H. Kerr, P. Waldteufel, J.-P. Wigneron, J.-M. Martinuzzi, J. Font, and M. Berger, "Soil moisture retrieval from space: The Soil Moisture and Ocean Salinity (SMOS) mission," IEEE Trans. Geosci. Remote Sens. vol. 39, no. 8, pp. 1729-1735, Aug. 2001.

[2] "Aquarius," 2004 ESE Reference Handbook, pp. 99-102, 2004. [Online] Available: http://aquarius.gsfc.nasa.gov/images/Aquarius_ese.pdf

[3] B. Tranchant, L. Renault, C.-E. Testut, N. Ferry, and P. Brasseur, "OSSE performed with simulated SMOS/Aquarius SSS data and the SAM2 scheme," Mercator Ocean Scientific Newslett., Apr. 2006. 
[4] P. Lazure, A.-M. Jégou, and M. Kerdreux, "Analysis of salinity measurements near islands on the French continental shelf of the Bay of Biscay," Sci. Mar, vol. 70, no. S1, pp. 7-14, 2006.

[5] I. Puillat, P. Lazure, A.-M. Jégou, L. Lampert, and P. I. Miller, "Hydrographical variability on the French continental shelf in the Bay of Biscay, during the 1990s," Cont. Shelf Res., vol. 24, no. 10, pp. 1143-1163, Jun. 2004.

[6] T. Pellarin, J.-P. Wigneron, J.-C. Calvet, M. Berger, H. Douville, P. Ferrazzoli, Y. H. Kerr, E. Lopez-Baeza, J. Pulliainen, L. P. Simmonds, and P. Waldteufel, "Two-year global simulation of L-band brightness temperatures over land," IEEE Trans. Geosci. Remote Sens., vol. 41, no. 9 , pp. 2135-2139, Sep. 2003.

[7] P. Waldteufel, J. Boutin, and Y. Kerr, "Selecting an optimal configuration for the Soil Moisture and Ocean Salinity mission," Radio Sci., vol. 38, no. 3, p. 8051 , Mar. 2003.

[8] P. Waldteufel and G. Caudal, "About off-axis radiometric polarimetric measurements," IEEE Trans. Geosci. Remote Sens., vol. 40, no. 6 , pp. 1435-1439, Jun. 2002.

[9] J. Boutin, P. Waldteufel, N. Martin, G. Caudal, and E. P. Dinnat, "Surface salinity retrieved from SMOS measurements over the global ocean: Imprecisions due to sea surface roughness and temperature uncertainties,' J. Atmos. Ocean. Technol., vol. 21, no. 9, pp. 1432-1447, Sep. 2004.

[10] E. P. Dinnat, J. Boutin, G. Caudal, J. Etcheto, and P. Waldteufel, "Influence of sea surface emissivity model parameters in L-band for the estimation of salinity," Int. J. Remote Sens., vol. 23, no. 23 pp. 5117-5122, Dec. 2002.

[11] L. A. Klein and C. T. Swift, "An improved model for the dielectric constant of sea water at microwave frequencies," IEEE Trans. Antennas Propag., vol. AP-25, no. 1, pp. 104-111, Jan. 1977.

[12] S. L. Durden and J. F. Vesecky, "A physical radar cross-section model for a wind-driven sea with swell," IEEE J. Ocean. Eng., vol. OE-10, no. 4 pp. 445-451, Oct. 1985.

[13] S. H. Yueh, "Modeling of wind direction signals in polarimetric sea surface brightness temperatures," IEEE Trans. Geosci. Remote Sens., vol. 35, no. 6, pp. 1400-1418, Nov. 1997

[14] P. Waldteufel and S. Zine, "Approximating the weighting function to be used in the SMOS L2 processor," 2005. Technical note SO-TN-CBSAGS-0010. [Online]. Available: http://www.cesbio.ups-tlse.fr/data_all/ SMOS-doc/CBSA/CBSA-GS-0010-1.b.pdf

[15] F. Petitcolin, P. Waldteufel, and J.-L. Vergely, "Final report of the study 'Soil moisture retrieval for SMOS mission'," 2003. ESA contract 16027/02/NL/GS, SMOS-FR-ACR-SA-007.

[16] E. Anterrieu, P. Waldteufel, and A. Lannes, "Apodization functions for 2-D hexagonally sampled synthetic aperture imaging radiometers," IEEE Trans. Geosci. Remote Sens., vol. 40, no. 12, pp. 2531-2542, Dec. 2002.

[17] P. Lazure and A.-M. Jégou, "3D modelling of seasonal evolution of Loire and Gironde plumes on Biscay Bay continental shelf," Oceanol. Acta, vol. 21, no. 2, pp. 165-177, Mar. 1998.

[18] J. P. Snyder, "An equal-area map projection for polyhedral globes," Cartographica, vol. 29, no. 1, pp. 10-21, 1992.

[19] F. Petitcolin, J. Boutin, J.-L. Vergely, P. Waldteufel, N. Reul, and J. Font, "Final report of the study "Soil moisture retrieval for SMOS mission'," CCN2 for Sea Surface Salinity Retrieval, 2005. ESA Contract 16027/02/NL/GS, SMOS-TN-ACR-LOD-006.

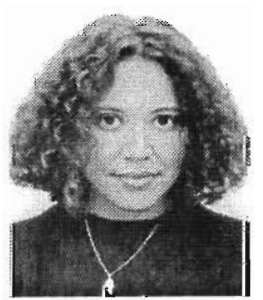

Sonia Zine received the Ph.D. degree from the University of Marne-la-Vallée, Marne-la-Vallée, France, in 2004 , where she studied the potential of scatterometer and SAR data to monitor land surface parameters in semiarid areas.

In 2005, she joined the Laboratoire d'Océanographie et du Climat-Expérimentation et Approches Numériques (LOCEAN), Paris, France, working on the Soil Moisture and Ocean Salinity (SMOS) mission. Her main research interests are passive and active microwave remote sensing of the Earth from space.

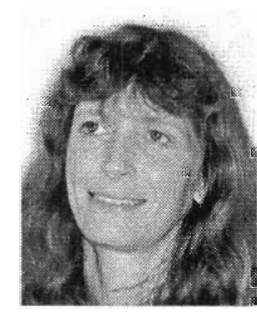

Jacqueline Boutin received the Ph.D. degree in physical methods in remote sensing from the University Paris VII, Paris, France, in 1990

She is currently a Research Scientist at Centre National de la Recherche Scientifique (CNRS) in Laboratoire d'Océanographie et du ClimatExpérimentation et Approches Numériques (LOCEAN), Paris. She has widely studied the validity of remotely sensed wind speeds and the ocean/atmosphere exchange of $\mathrm{CO}_{2}$ at large scale using both satellite (wind speed, SST, ocean color) and in situ data (in particular, CARIOCA autonomous drifters). Since 1999 she is involved in the preparation of the Soil Moisture and Ocean Salinity (SMOS) mission: She participated to the development of an $L$-band sea surface emissivity model and to several airborne campaigns (WISE, Eurostarrs). She is a member of the ESA expert support laboratories that define and validate the processing of SMOS level 2 measurements for the retrieval of sea surface salinity.

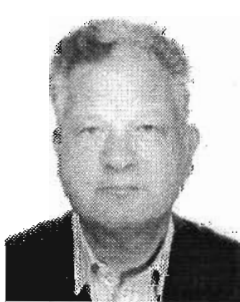

Philippe Waldteufel received the Engineering degree from the Ecole Polytechnique, Paris, France, in 1962, and the Doctorat d'Etat degree from the Université de Paris, Paris, France, in 1970.

$\mathrm{He}$ is a Senior Scientist at the Centre National de la Recherche Scientifique, Verrières le Buisson, France. His main scientific interests have been ionospheric and thermospheric physics, radar meteorology, radiowave propagation, macroeconomics, and finally, microwave radiometry. $\mathrm{He}$ has also served as Director of the Institut de Physique du Globe de Clermont-Ferrand, Deputy Director in the French Weather Service Research Department, and Director for Science in the French Research Ministry.

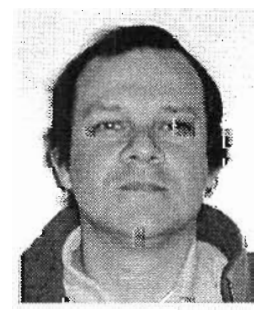

Jean-Luc Vergely received the Engineering degree from the Ecole Nationale du Génie des Eaux et de l'Environnement de Strasbourg, France, in 1988, and the Ph.D. degree in statistics applied to astronomy from Louis Pasteur University, Strasbourg, France, in 1998.

He managed cooperative projects in Africa. He is currently with ACRI-ST, Sophia-Antipolis, France.

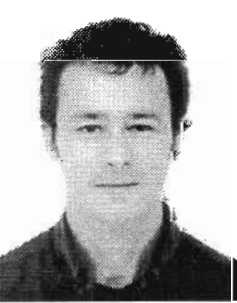

Thierry Pellarin was born in Versailles, France, in 1972. He received the $\mathrm{Ph} . \mathrm{D}$. degree from the University of Grenoble, Grenoble, France, in 2001. His thesis work concerned the use of weather radars for hydrological applications in mountainous regions.

In the framework of the Soil Moisture and Ocean Salinity (SMOS) mission, he was with the Centre National de Recherches Météorologiques, Toulouse, France (2001-2003), and the Centre d'Etudes Spatiales de la BIOsphere (CESBIO, Toulouse) in 2004. He is currently a Research Scientist at Laboratoire d'études des Transferts en Hydrologie et Environnement (LTHE, Grenoble, France). His current main field of interests is in microwave radiometry, with particular emphasis on the African Monsoon Multidisciplinary Analysis project.

Pascal Lazure, photograph and biography not available at the time of publication. 